\title{
SPATIOTEMPORAL ENTANGLEMENTS
}

\section{Insights from history}

\author{
Susanne Rau
}

\section{Introduction}

While there is much to be said for investigating the influence of current social processes (such as digitalization or globalization) on spatial arrangements, as sociologists Hubert Knoblauch and Martina Löw (2017) have set out to do, it is equally important to analyze the relationship between space and time or between spatiality and temporality. Spaces or spatial arrangements change in the course of transformation processes, but so too does the relationship between space and time.

Since it is not possible to tell the whole story of space-time in this context, I instead refer to the work of the "SpatioTemporal Studies" group, a research group at the University of Erfurt, and briefly outline its guiding principles. Furthermore, since the history of the interrelationship of space and time cannot be described in just a few pages, I will fall back on a few illustrative examples that show how space and time have been graphically and cartographically represented in their interrelation. The examples come from the European Middle Ages and the early modern period. These singular examples can at least serve to illustrate that even in the pre-modern age, there must have been - if not a theory of space-time-at least an awareness of the entanglement of space and time.

I will start with a counterfactual argument ("history without time?"), then move on to a short presentation of the ideas and ongoing research activities of the Erfurtbased "SpatioTemporal Studies" group before I discuss the pre-modern understanding of the relationship of spatiality and temporality, followed by some examples.

\section{History without time?}

A counterfactual argument should be considered first (Rau 2019, 40-41). What would history be without time? (The same question can, of course, also be asked 
in relation to space.) In recent years, spatial theories and, in particular, Löw's (2001) sociology of space have been widely received in the historical sciences. Löw's relational approach has focused primarily on the constitutional processes of social spaces (operations of placement or "spacing" followed by operations of conceptual synthesis). The reception of the spatial turn in history has sometimes led to the paradoxical situation that spatial orders have been given priority over temporal ones.

With a more specific definition of space-as an organizational form of coexistence that makes synchronicity or simultaneity visible-we reach a point where we must ask what history we are actually writing when we continue to ignore temporal aspects such as succession, sequentiality, diachronicity, procedurality, or acceleration. It would of course be worth trying to write a history in a purely locative mode. But, as long as we human beings experience time as passing and spaces as changing, this would hardly make sense. We should thus continue to combine spatial aspects with temporal aspects.

Space, namely, cannot be understood at all in its complexity if we do not include the factor of time and multiple temporalities. This interrelatedness of spatiality and temporality can be founded both theoretically and practically in relation to our everyday lives, since we would not even be able to think or live in just one category or the other. Whoever wants to remain standing in just one place, to neither move nor change anymore? The same holds true for the historical subjects and the spatial phenomena under examination. When we take interest in historical subjects and their environments, practices, feelings, and interpretations in a comprehensive human sense, taking both dimensions into consideration cannot be avoided. If the intention is to capture subjects within their complex relations with their environment-and not, in other words, only through their spatial relation with their surroundings - everything suggests that we should call our considerations "historic-anthropological."

The second reason for choosing the designation "historic-anthropological" is that these relationships do not remain anthropologically constant but rather change over time, diachronically, and these changes are in no way simply linear. This perspective thus differs from many historical-geographic approaches inasmuch as time appears to stand still in these approaches, or because changes are represented as linearly homogeneous (for example, in a scheme of before/after). This can often be seen, for example, in topographic charts of cities in older history books.

A third reason for calling our approach "historic-anthropological" is that historicity also means taking into consideration the potential difference of spatial constructs and constellations in different cultures or contexts. However, this is not as yet sufficient to propose a thesis on the indivisibility of spatiality and temporality.

In creating and developing such methodological instruments, we need not start from scratch: various non-historical disciplines have already brought forth interesting approaches to this problem which we can use as a point of departure. For geography, the Swede Torsten Hägerstrand developed a time-geography in the early 1970s. Through the translation of his works into English, his approach has gained international recognition and was incorporated, not least, into the structuration theory of sociologist 
Anthony Giddens (Giddens 1997, 168; Gregory 1984; Stjernström 2004). On the one hand, Hägerstrand (1970) engaged with large-scale geographies. Yet, on the other, he also examined movements of people in what he called "action spaces," defined as the set of spatial possibilities and limitations of action available to an individual. As a geographer, Hägerstrand set out to examine all spatial and temporal levels that play a role in the life of an individual - from their living quarters to the globe, from a single day to the span of their life. Temporalization of space can thus be examined from perspectives of limitation of use (of space), the specification of duration, or the elasticity of activities.

By contrast, the spatialization of time can be understood as the "patterning of time" by individuals who are in turn dependent on the distribution of spatial possibilities (Carlstein, Parkes, and Thrift 1978).

As can easily be seen, temporality is an important dimension of space, both theoretically speaking and in everyday life, then as now. The Erfurt research group therefore thinks of spatiality and temporality together, as will be briefly explained hereafter.

\section{The "SpatioTemporal Studies" group}

From a conceptual perspective, "SpatioTemporal Studies" assumes that, in everyday life, spatiality and temporality cannot be separated from each other in their constructedness. This interdisciplinary research group strives to provide new impulses in the theoretical debate on space in the social and cultural sciences as well as to promote the regionalization and historicization space and time. Its members come from the fields of history, literature, religious studies, geography, art history, philosophy, and theology.

Another focus lies in the spatial and temporal practices of historical actors and groups. As historians, we see as one of our tasks to historicize spatial theories and to discover spatiotemporal concepts and practices in times long before the socalled spatial turn - which is an empty shell, as it does not offer any agreed upon methodology or common language. We should therefore speak of "spatial turns," in the plural, instead. Either way, theories about and beyond the "spatial turn" have taught us that spaces are no longer regarded as something simply physically given (Lefebvre 1991; Werlen 1995-1997; Löw 2001), but rather as something socially constructed. Spaces are the result of negotiations and designs, and these take place in time. An example of this approach and interdisciplinary collaboration is the project on the spatiotemporality of imperial practices of governance and ruling. In the course of imperial aspirations, new space-time constellations have been not only created but also represented in a wide range of media since antiquity (Meyer, Rau, and Waldner 2017a). The positive echo of the conference "Spacetime of the Imperial" and the homonymic volume highlight the growing interdisciplinary interest in an integrated view on the history of spatial patterns and their dynamics (Kirchberger 2018; see also Dorsch and Vinzent 2018; Bauer and Fischer 2019; Schmolinsky, Hitzke, and Stahl 2019; for further volumes, see Dorsch et al. 2017-2020). 
Another project on historical urban planning processes, conducted within the same framework a couple of years ago, also revealed the fruitfulness of such an integrated view, in the sense that it could further the understanding of a complicated spatiotemporal process-especially when taking into account that many spatial expansion projects have been discussed but never realized. This is probably still the case today, but it has not yet been applied to urban planning history. The study dealt with two major expansion projects in the city of Lyon in the 18th century (Rau 2013). The crucial point here is that one should not look only at the physical results of this process. Through a detailed analysis of historical sources (from architects, the city council, the Academy of Sciences, and travel reports) over a period of more than one hundred years, it was possible to demonstrate that the history of planning and process of shaping the urban periphery often resembled a dialectical movement of spatial visions and partial failure, entailing temporal setbacks that, in the end, led to a synthesis of the half-planned and half-unforeseen. Yet, many spatial theories, including those that emphasized the role of capital in the production of space, offer insufficient explanations of the complex spatiotemporality of urbanization processes. It was thus proposed against the backdrop of the Lyon projects - which were already doing much of what was happening in many European cities in the 19th century - that a description of processes of urban (meaning spatial) expansion must take into account such temporal phenomena as vision, retrospection, hope, and delay.

\section{Theories and methods of cultural space-time}

The main theoretical input for the Erfurt research group stems from Mikhail Bakhtin, Henri Lefebvre, and Michel de Certeau.

One of the most well-known models of spatiotemporality is the concept of the "chronotope," derived around 1940 from the ideas of Mikhail Bakhtin, which strives to find a modeling of space and time that is characteristic for a particular epoch or formation (Meyer, Rau, and Waldner 2017b, 4). Bakhtin understood chronotope to mean the "intrinsic connectedness of temporal and spatial relationships that are artistically expressed in literature." (Bakhtin 1981, 84-85)

Derived from mathematics and Einstein's theory of relativity, Bakhtin used the category to examine the relations of time and space in literature. According to Bakhtin, the two categories belong together, forming each other and structuring any narrative. Time only gives meaning to places and spaces in narratives (or novels). The chronotope is therefore somewhat like the condition of the possibility of a narrative. First developed for the analysis of narratives, the concept can be extended and applied to the changing spatiotemporal structures (of images) of the world and of humankind ( $\mathrm{Rau} 2019$, 96). That would not have been against Bakhtin's intentions, as he also saw himself as a cultural scientist.

To Henri Lefebvre, the group owes the emphasis on the historicity and culturality of spaces. In essence, Lefebvre expressed this through the following statement: "Every society . . p produces a space, its own space. . . [example:] . . the ancient 
city had its own spatial practice: it forged its own - appropriated — space" (translation from the French original text by Rau 2019, 28). Historicity in this context means that each time or epoch must be seen under its specific conditions. Besides historicity (as past temporality), Lefebvre $(1991,48)$ also defended a concept of processes and of epochal divisions, which was strongly influenced by Marxist historiography:

The history of space cannot be limited to the study of the special moments constituted by the formation, establishment, decline and dissolution of a given code. It must deal also with the global aspect-with modes of production as generalities covering specific societies with their particular histories and institutions. Furthermore, the history of space may be expected to periodize the development of the productive process in a way that does not correspond exactly to widely accepted periodizations.

The new periodization or epochal classification claimed here must by no means follow Marxist historiography (such as: ancient slaveholder society, the medieval feudal society, modern capitalism, communism). Those who recognize Lefebvre's appeal will look for a periodization that turns the important changes in spatial constellations into epochal turns, which can vary from region to region.

The third favorite theoretician of the research group is Michel de Certeau, with his emphasis on stories and practices of space.

In his Practice of Everyday Life, published in French in 1990, Certeau writes that narratives "organize" places; they single them out and connect them with each other. He formulated the saying "every story is a travel story," a spatial practice (Certeau 2011, 115; Rau 2019, 70-73). Narratives, in other words, do not simply transpose steps into the level of language. They organize these steps, make the "journey," and create geographies of action. By combining syntax and practices, Michel de Certeau brought together spatial stories and spatial practices. This means, for example, if we describe a walk through a city, we are not simply describing a distance from one place to another, but rather are subjectively organizing an urban space and appropriating it, ensuring we can remember it and make it available to others.

These approaches from the social and cultural sciences dating back to the 20th century are also reflected in the semantic history and even have an older history.

\section{Views from conceptual and semantic history}

In most languages, the word combination "spatiotemporal" or "spatiotemporality" does not appear before 1900. Moreover, Albert Einstein was probably the first to provide a theory of "space-time" in which time, as a fourth dimension, is closely linked to the three dimensions of space. But this is physics (for a sociology of spacetime, see Weidenhaus 2015). As far as everyday language is concerned, we find references in the Merriam-Webster dictionary where "spatiotemporal" is defined in two senses: 
1 "Having both spatial and temporal qualities"

2 "Of or relating to space-time"1

According to the dictionary, which was founded in 1828, the first known use of the adjective "spatiotemporal" appeared in 1900, in the meaning of the first definition.

However, these findings do not necessarily mean that the notion or idea of an entanglement of space and time did not exist in earlier times. We can also find them in practices and in media such as tables and maps.

Although it may be quite clear that before the 20th century there was no theory of space-time (and also no notion of time as the fourth dimension of space), the history of language has left traces of the connection between space and time.

Thus, for example, "space" (espace) can be proven in the meaning of "duration" (durée) in French as early as the 12th century. In other words, if someone spoke about an extended time, or a period of time (from-to), they used the word "espace."

The adjective "geraum" exists in German, which was initially only used for spatial determinations. Since the 15th century, it has also appeared with a temporal meaning — as we still say today, "seit geraumer Zeit," which translates to "for quite some time." If this idea is expressed differently-for example, using the phrase "seit langem" ("for a long time")—one can assume that the speaker has a three- if not four-dimensional conception of duration.

\section{Entanglements of space and time as reflected in historical discourse and media}

Representations of the spatiality of time can also be found in the history of historiography and cartography. Time courses and stories were conveyed in not only text form but also in graphic representations of time. Basically, this began with the medieval annals, in which year after year the most important events were written down, which in principle must have evoked a linear course of time when reading (see Figure 5.1).

The chronicle of Eusebius was written at the beginning of the 4th century but was copied and amended several times during the Middle Ages. Thus, the graphic form of the history in tables, in which events of different empires are arranged in columns next to each other and listed in annual steps, was also handed down until early modern times.

In this tradition, European circles of scholars graphically represented time and history in the form of "tabulae," "tables historiques," "tables universelles," "chronological tables," "views of universal history," or "Tabellenwerke." These history tables and diagrams are often provided with vectors or at least suggest a temporal sequence through the viewing and reading direction. Above all, however, the temporalized events take up space: first of all, space on paper. In the figurative sense, however, time periods (alias duration) are symbolized again: time period of an event, time period of a reign, time period of an entire epoch or "empire," as expressed in 


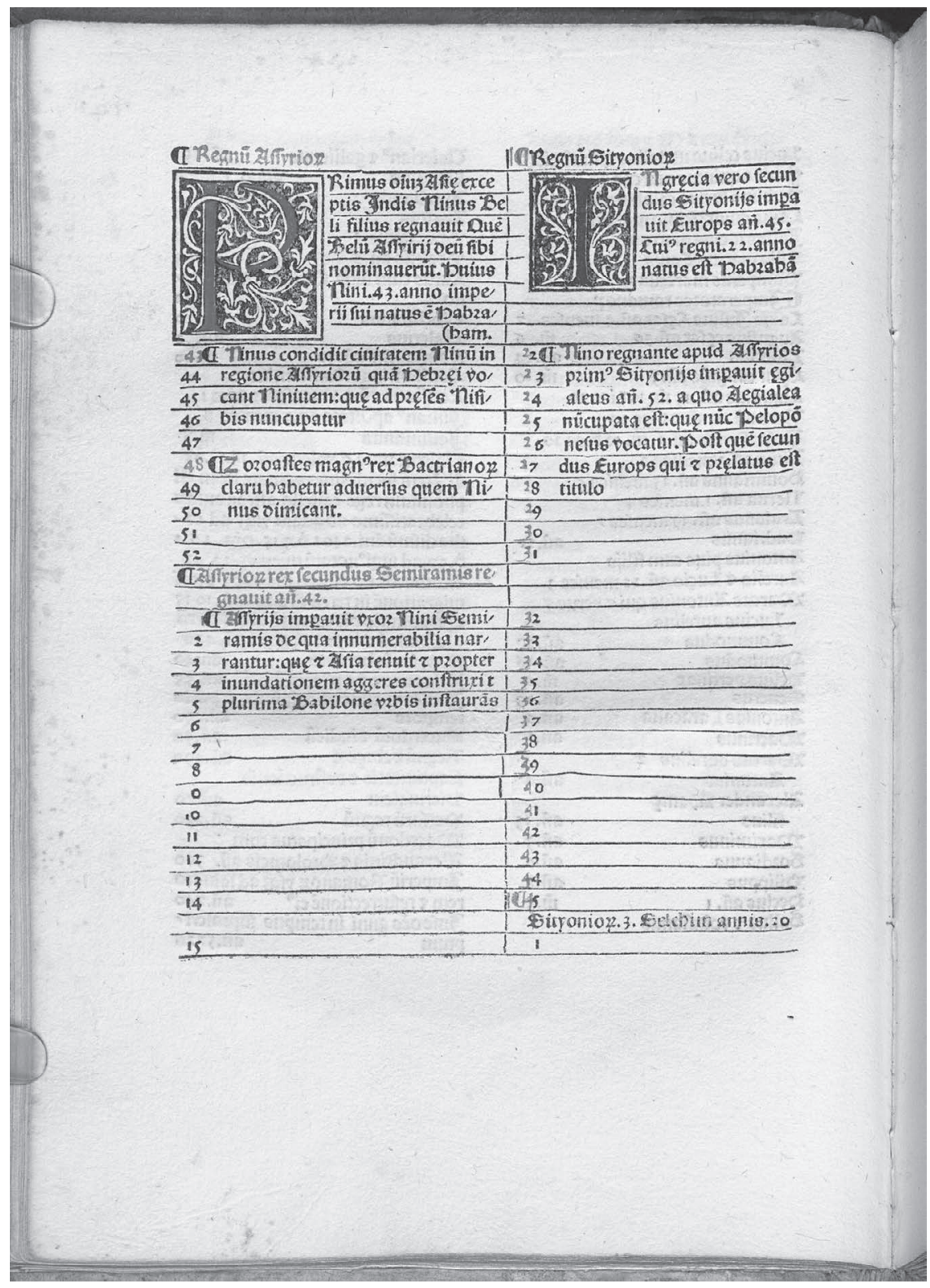

FIGURE 5.1a Example for graphic representation of time as chronological table

Source: Chronicon Eusebii, a sancto Hieronymo latine versum et ab eo, Prospero Britannico et Matthaeo Palmerio continuatum, editum cura C. L. Johannis Hippodami. Venice: E. Ratdolt, 1483. Bayerische Staatsbibliothek München, 4 Inc.c.a. 290 , fol. $14 \mathrm{v}$ and $15 \mathrm{r}$. 


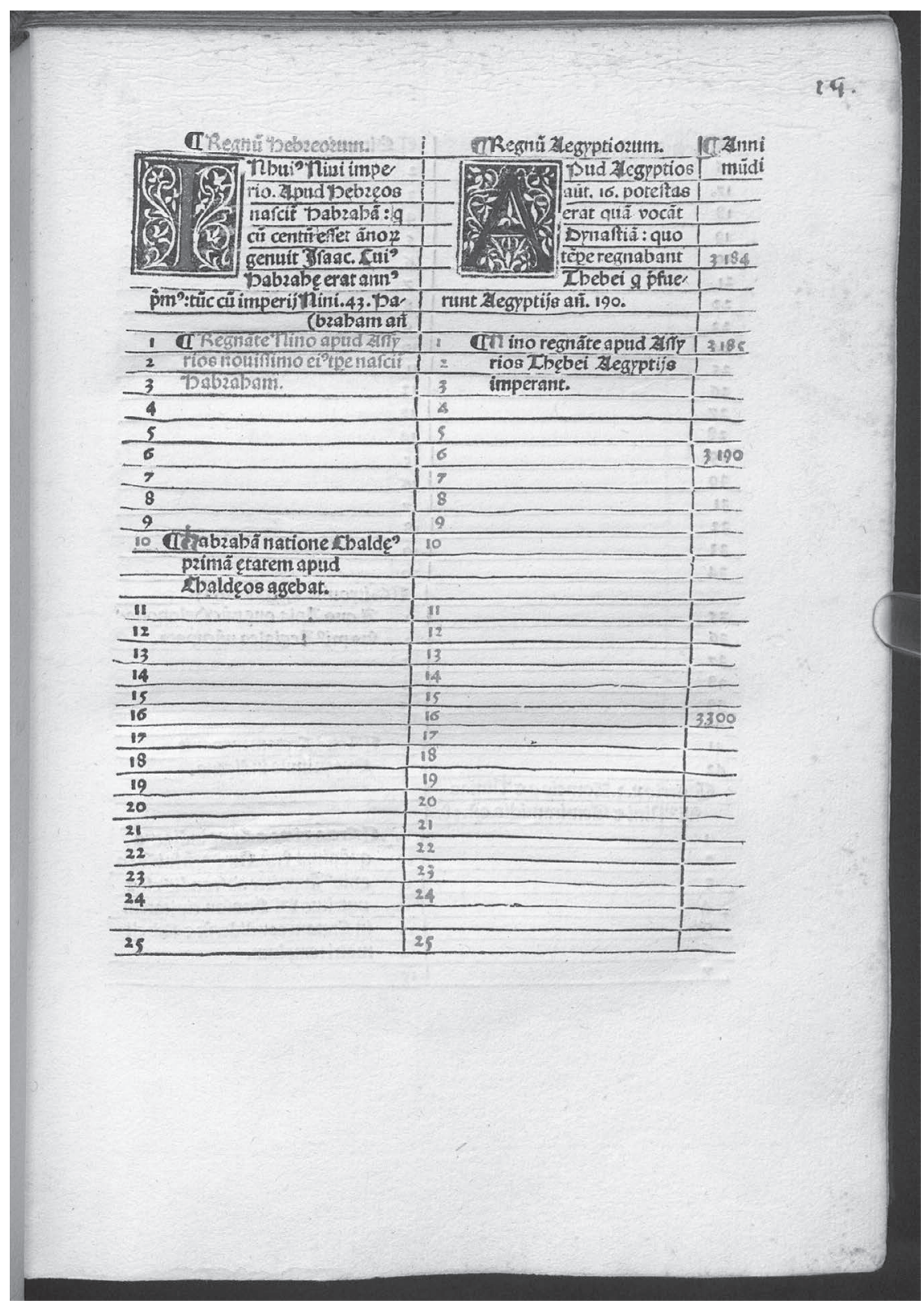

FIGURE 5.1b (Continued) 
the context of the concept of the four-monarchy or seven-empire doctrine. An example of this is the "Chart of History" by British polymath Josef Priestley, who designed the chart as teaching material for students and put on it - according to his claim - the entire history of the world with its most important events and localities (see Figure 5.2).

In contrast to Thomas Jefferson's "Chart of Universal History" of 1753, Priestley regularized the distribution of dates on the chart and oriented it horizontally to emphasize the continuous flow of historical time (Rosenberg and Grafton 2010, 120-121). In this sense, the historical chart is a space-time medium.

A further development of these chronological tables is historical maps, which sometimes also contain temporal information or are even converted into graphical form. These hybrid maps then combine geographic and temporal information. An early example of this is the "Carta istorica dell'Italia e d'una parte della Germania," drawn and published by Girolamo Andrea Martignoni in 1721 (see Figure 5.3).

Compared to Priestley's charts, Martignoni's historical maps used typical elements of a map - territories, bodies of water (oceans, lakes, rivers), geographic names - but less text than on the charts, together with a series of symbols and icons. But the rivers are not simply geographical elements. Especially on the upper map sheet, they represent the flow of time (Rosenberg and Grafton 2010, 108).

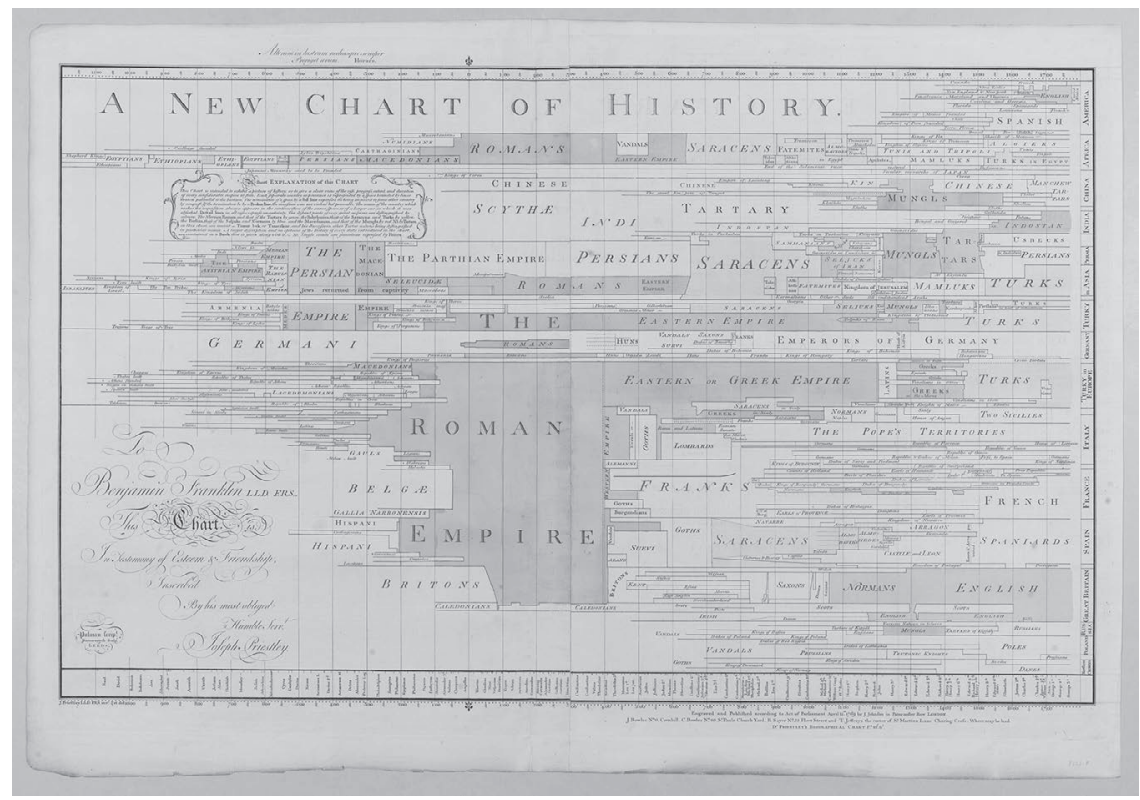

FIGURE 5.2 Example for graphic representation of time as spatialized charts

Source: Joseph Priestley. 1769. A New Chart of History. Wikimedia Commons, Public Domain. https:// commons. wikimedia.org/w/index.php?curid=25092379 


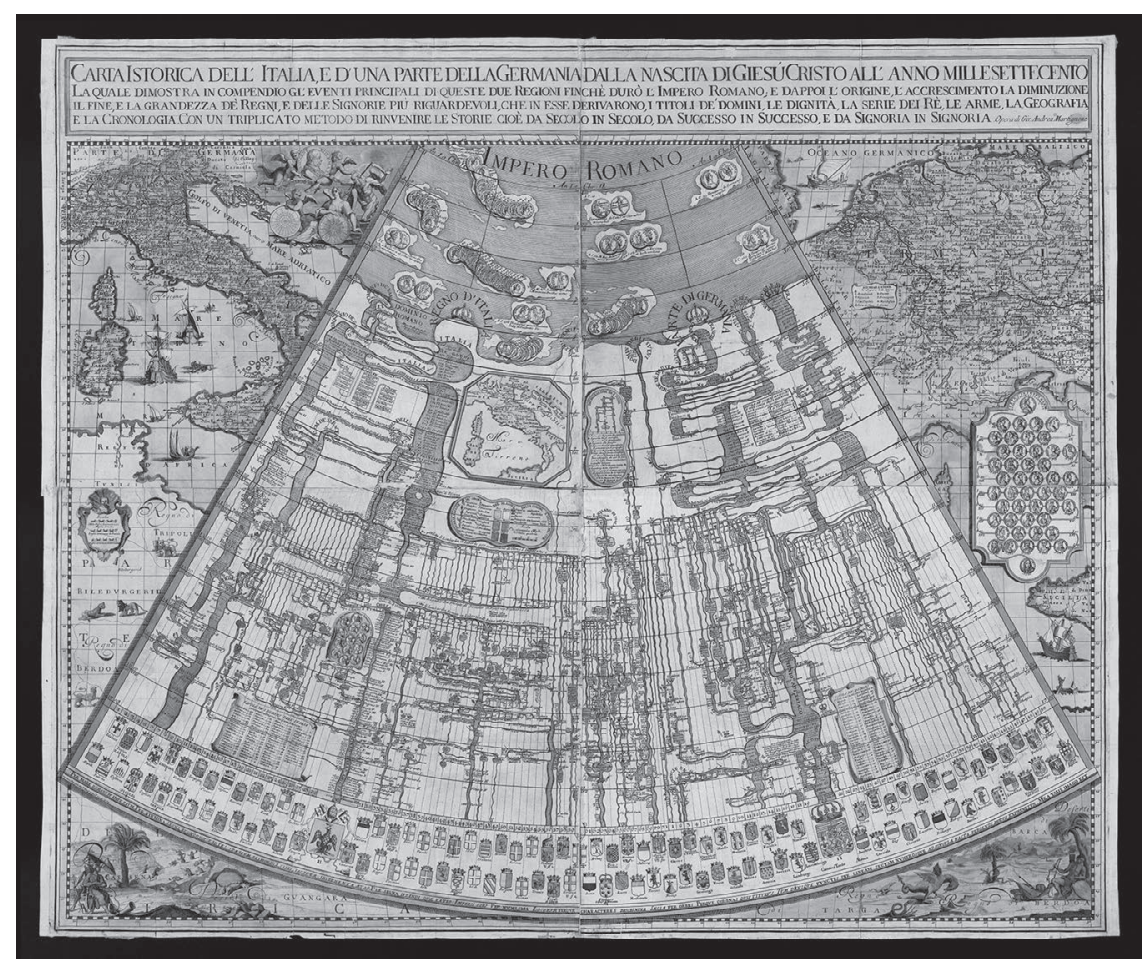

FIGURE 5.3 Example for hybrid map

Source: Girolamo Andrea Martignoni and Giovanni Petroschi. 1721. Carta istorica dell'Italia, e d'una parte della Germania dalla nascita di Giesú Cristo all'anno millesettecento. Rome. Institut Cartogràfic i Geològic de Catalunya (ICGC), RM.220396

Thus, these "rivers of time" on the historical maps depict the fact that history is in motion, that it itself changes geographical objects (e.g., the "Impero Romano" at the top of the map).

\section{Conclusion}

My starting point was that spatiality cannot be understood without temporality (the reverse is also true), because they are mutually dependent on and form each other. The demand of the various voices in the "spatial turn" to pay more attention to space and to analyze the constitutional processes of social space in a more differentiated way is certainly justified. However, this claim has also led in part to one-sidedness, such as the paradoxical neglect of temporality. With my considerations, I have attempted to show that this does not make sense from a historicalanthropological point of view, because people need spatial and temporal categories in their world relations, both for orientation and in retrospective description. The 
fact that it is only since Einstein that we have had a(n initially physical) theory of space-time should not prevent us from looking into history and other cultures and asking about their perceptions, practices, and representations of this relationship. My short contribution was only able to present a few highlights in this regard. Both conceptual history and various attempts to represent history graphically (in tables or on maps) bear witness to older efforts to think of space and time together and to represent them in their interdependence. Considering the multiple temporalities of space could also be a meaningful extension of the concept of "re-configuration of spaces," since it is used to investigate processes in the social world that are certainly not linear.

\section{Note}

1 Space-time, "a system of one temporal and three spatial coordinates by which any physical object or event can be located" (see www.merriam-webster.com/dictionary/ space-time [8.2.2019]), appeared for the first time in 1910. Spatiotemporal: www. merriam-webster.com/dictionary/spatiotemporal\#examples (8.2.2019). The entry "spatiotemporality" does not exist. For German language usage, see DWDS: www.dwds. de/. "Raumzeitlichkeit" appears only in the 20th century. No entry in the Wörterbuchnetz, a digital platform for historical dictionaries: www.woerterbuchnetz.de/cgi-bin/ WBNetz/setupStartSeite.tcl. Only the Grimm contains the keyword "temporality" in the sense of transience.

\section{References}

Bakhtin, Mikhail. 1981. "Forms of Time and of the Chronotope in the Novel." In The Dialogic Imagination. Translated by Caryl Emerson and Michael Holquist, 84-258. Austin: University of Texas Press.

Bauer, Jenny, and Robert Fischer, eds. 2019. Perspectives on Henri Lefebvre: Theory, Practices and (Re)Readings. Berlin: de Gruyter.

Carlstein, Tommy, Don Parkes, and Nigel Thrift, eds. 1978. Timing Space and Spacing Time, 3 Vols. London: Edward Arnold.

Certeau, Michel de. 2011. The Practice of Everyday Life. Translated by Steven Rendall. Berkeley: University of California Press.

Dorsch, Sebastian, Bärbel Frischmann, Holt Meyer, Susanne Rau, Sabine Schmolinsky, and Katharina Waldner, eds. 2017-2020. SpatioTemporality/RaumZeitlichkeit. Book series. Berlin: de Gruyter. www.degruyter.com/view/serial/SPATIO-B?contents=toc-59654.

Dorsch, Sebastian, and Jutta Vinzent, eds. 2018. SpatioTemporalities on the Line. RepresentationsPractices-Dynamics. Berlin: de Gruyter.

Giddens, Anthony. 1997. Die Konstitution der Gesellschaft. Grundzüge einer Theorie der Strukturierung, 3rd ed. Frankfurt am Main: Campus.

Gregory, Derek. 1984. "Space, Time and Politics in Social Theory: An Interview with Anthony Giddens." Environment and Planning D: Society and Space 2 (2): 123-132.

Hägerstrand, Torsten. 1970. "What About People in Regional Science?" Papers of the Regional Science Association 24: 7-21.

Kirchberger, Ulrike. 2018. "Holt Meyer/Susanne Rau/Katharina Waldner (Eds.), SpaceTime of the Imperial. (SpatioTemporality/RaumZeitlichkeit, Bd. 1.) Berlin/Boston, De Gruyter 2017." Historische Zeitschrift 307 (3): 753-755. doi: 10.1515/hzhz-2018-1510. 
Knoblauch, Hubert, and Martina Löw. 2017. "On the Spatial Re-Figuration of the Social World.” Sociologica 11 (2): 1-27. doi: 10.2383/88197.

Lefebvre, Henri. 1991. The Production of Space. Translated by Donald Nicholson-Smith. Oxford: Blackwell.

Löw, Martina. 2001. Raumsoziologie. Frankfurt am Main: Suhrkamp.

Meyer, Holt, Susanne Rau, and Katharina Waldner, eds. 2017a. Spacetime of the Imperial. Berlin: de Gruyter.

Meyer, Holt, Susanne Rau, and Katharina Waldner. 2017b. ““. . . this smooth space of Empire ... 'Introduction to Six Spatiotemporal 'Stabs' at Analyzing the Imperial.' In Space Time of the Imperial, edited by Holt Meyer, Susanne Rau, and Katharina Waldner, 1-20. Berlin: de Gruyter.

Rau, Susanne. 2013. "The Urbanization of the Periphery: A Spatio-Temporal History of Lyon Since the Eighteenth Century." Historical Social Research 38 (3): 150-175.

Rau, Susanne. 2019. History, Space, and Place. Translated by Michael Thomas Taylor. London: Routledge.

Rosenberg, Daniel, and Anthony Grafton. 2010. Cartographies of Time: A History of the Timeline. New York: Princeton Architectural Press.

Schmolinsky, Sabine, Diana Hitzke, and Heiner Stahl, eds. 2019. Taktungen und Rhythmen. Raumzeitliche Perspektiven interdisziplinär. Berlin: de Gruyter.

Stjernström, Olof. 2004. "Theory and Migration: Towards a Framework of Migration and Human Actions.” Cybergeo: European Journal of Geography. doi: 10.4000/cybergeo.3827.

Weidenhaus, Gunter. 2015. Soziale Raumzeit. Berlin: Suhrkamp Verlag.

Werlen, Benno. 1995-1997. Sozialgeographie alltäglicher Regionalisierungen, 2 vols. Stuttgart: Franz Steiner Verlag. 